\title{
PADRONIZAÇÃO DE TESTE DE POTÊNCIA IN VITRO PARA VACINAS QUE CONTENHAM TOXOIDE ALFA DE CLOSTRIDIUM NOVYI TIPO B
}

\section{C.G.R.D. Lima ${ }^{1}$, Z.I.P. Lobato ${ }^{2}$, P.S. Pires ${ }^{1}$, R.O.S. Silva ${ }^{1}$, F.M. Salvarani ${ }^{1}$, R.A. Assis ${ }^{3}$, F.C.F. Lobato ${ }^{1}$}

${ }^{1}$ Universidade Federal de Minas Gerais, Escola de Veterinária, Laboratório de Bacteriose e Pesquisa, Av. Antonio Carlos, 6627, CEP 30123-970, Belo Horizonte, MG, Brasil. E-mail: flobato@vet.ufmg.br

\section{RESUMO}

\begin{abstract}
Clostridium novyi tipo B é o patógeno responsável pela hepatite necrótica, causada pela ação da toxina alfa. O controle desta enfermidade é baseado na imunização dos animais com vacinas que contenham na sua composição toxóide alfa de C. novyi tipo B. O teste de potência deste imunógeno é realizado a partir de soros de coelhos imunizados, por meio da técnica de soroneutralização em camundongos. Portanto objetivou-se padronizar um teste de potência de toxóide alfa de C. novyi tipo B em linhagem de célula VERO, como método alternativo ao bioensaio animal. O coeficiente de correlação obtido pelas técnicas in vitro e in vivo foi de $98,38 \%$, indicando ser possível a utilização do modelo estudado na substituição do modelo animal para teste de potência de toxoide alfa de C. novyi tipo B.
\end{abstract}

PALAVRAS-CHAVE: Clostridium novyi tipo B, soroneutralização, vacinas, bioética.

\section{ABSTRACT}

STANDARDIZATION OF AN IN VITRO POTENCY TEST FOR VACCINES CONTAINING CLOSTRIDIUM NOVYI TYPE B ALPHA-TOXOID. Clostridium novyi type B is the pathogen responsible for necrotizing hepatitis caused by the action of alpha toxin. The control of this disease is based on immunization of animals with vaccines containing alpha toxoid of $C$. novyi type B in its composition, and the evaluation of this toxoid is made by seroneutralization in mice. Therefore, the present study was aimed to standardize a test of the power of alpha toxoid of C. novyi type B cell line VERO, as an alternative to animal bioassay The correlation coefficient obtained by the in vitro and in vivo techniques was $98.38 \%$, indicating the possible use of the model to replace the animal model to test the power of alpha toxoid of C. novyi type B.

KEY WORDS: Clostridium novyi type B, soroneutralization, vaccine, bioethics.

\section{INTRODUÇÃO}

Clostridium novyi tipo Béo agenteetiológico da hepatitenecrótica, enfermidade geralmente associadaà morte súbita principalmente de ovinos, que acomete também outras espécies. Fatores predisponentes, como a presença de trematódeos hepáticos ou outros agentes que causam lesões hepáticas, resultam em condições favoráveis à multiplicação bacteriana, com consequente produção da toxina alfa, responsável pelo quadro patológico (Uzal et al., 1996; MYIASHIRO et al., 2006). Dentre as toxinas produzidas pelo $C$. novyi tipo B, a toxina alfa se destaca por sua ação necrosante e letal (HatheWAy, 1990). Em cultivo de células, esta toxina causa arredondamento celular, sugerindo efeito no citoesqueleto de células de mamíferos (BALL et al., 1993).
Devido às características do agente, que está presenteno solo eé comensal do trato gastrointestinal de animais ehumanos, a sua erradicaçãoé praticamente impossível. Portanto, o controle da enfermidade baseia-se principalmenteem medidas preventivas de manejo e vacinação sistemática de todo rebanho, uma vez que os animais estão em permanente contato com os agentes e com os fatores que podem desencadear a doença (Lobato; Assis, 2000).

A cada ano são produzidas no Brasil em torno de 150 milhões de doses de vacinas clostridiais. Apesar da significativa produção destas vacinas, não existe controle oficial que ateste a qualidade quanto à potência de todos os componentes destes imunobiológicos. O Ministério da Agricultura, Pecuária e Abastecimento avalia sistematicamente as bacterinas de C. chauvoei, os toxoides botulínicos tipo

${ }^{2}$ Universidade Federal de Minas Gerais, Escola de Veterinária, Laboratório de Virologia, Belo Horizonte, MG, Brasil.

${ }^{3}$ Laboratório Nacional Agropecuário de Minas Gerais (LANAGRO-MG), Pedro Leopoldo, MG, Brasil. 
C e D e, desde 2009, os toxóides beta e épsilon de C. perfringens tipo B, C e D. (GonçAlves et al., 2009).

A técnica oficialmente empregada para a realização do teste de potência de toxoides clostridiais é a soroneutralização em camundongos (BRITSH PHARMACOPEIA, 1998; US, 2005). Embora tenha reconhecida sensibilidade e segurança, esta é uma metodologia de custo relativamente elevado, demorada, que apresenta alguns resultados imprecisos devido a variações de sensibilidade individual, além de causar dor e sofrimento a um grande número de animais, gerando questionamentos éticos (WOOD, 1991; EBERT et al., 1999). Em contrapartida, o uso de cultivo de células na avaliação da potência de toxoides clostridiais pode ser um método alternativo e apresenta vantagens como a redução na variabilidade de resultados, dos custos com o teste, além de diminuir substancialmente o número de animais utilizados (Metz et al., 2002).

Desta forma, objetivou-se titular a toxina alfa de C. novyi tipo B e padronizar um teste de soroneutralização in vitro, em célula VERO (African Green Kidney Monkey), para avaliação da potência de vacinas que contenham o toxoide alfa, e estabelecer correlações entre o modelo padronizado e o bioensaio em camundongos sisteda medidao primeiro trabalho que avalia um método alternativo in vitro para titulação de anticorpos anti toxina alfa de $C$. novyi tipo B em soros de caprinos, ovinos e coelhos.

\section{MATERIAL E MÉTODOS}

\section{Toxina, antitoxina padrão, soros teste e cultivo celular}

A toxina alfa foi produzida a partir de uma amostra de cepa de referência de $C$. novyi tipo B (Animal and Plant Health Inspection Service - APHIS, EUA/ IRP-307) semeada em Meio de Cardella (CARDELLA et al., 1958) modificado pela adição de $0,5 \%$ de cloreto de sódio, $0,003 \%$ de sulfato de magnésio e $0,03 \%$ de L-cisteína, e incubado a $37^{\circ} \mathrm{C}$ em câmara de anaerobiose por $24 \mathrm{~h}$. Em seguida, a cultura foi centrifugada a $8000 \times$ x por 30 minutos a $4^{\circ} \mathrm{C}$, e o sobrenadante foi concentrado dez vezes por sistema de ultrafiltração tangencial com cartucho Pellicon (Millipore Corporation, EUA) de retenção de $10 \mathrm{kDa}$. A toxina foi filtrada em filtro $0,22 \mu \mathrm{M}$ e armazenada a $-80^{\circ} \mathrm{C}$ até sua utilização.

Antitoxina alfa de C. novyi tipo B (Gas Gangrene Antitoxin, Code Nr: 64/024), adquirida junto ao Nacional Institute for Biological Standards and Control (NIBSC, Inglaterra) foi utilizada tanto para a padronização da toxina alfa como para controle na titulação dos soros teste. Os soros teste foram obtidos de ovinos e de caprinos imunizados duas doses, via subcutânea, nos dias zero e 42, utilizando-se uma vacina comercial polivalente que continha o toxoide alfa de C. novyi tipo B em sua composição. Já os três pools de soro de coelhos foram obtidos a partir da imunização de oito coelhos por grupo, com três diferentes vacinas comerciais, com duas doses intervaladas de 21 dias,com o toxoideconizado pela British Pharmacopoeia (1998). A linhagem contínua VERO foicultivada em meioessencial mínimo(MEM) (Difico Laboratories, EUA), suplementado com 5\% (v/v) de soro fetal bovino (SFB) (Difco Laboratories, EUA) e $2 \mathrm{mM}$ de glutamina, $2 \mathrm{UI} / \mathrm{mL}$ de penicilina, $2 \mu \mathrm{g} / \mathrm{mL}$ de estreptomicina e $0,0125 \mu \mathrm{g}$ de fungizona. A linhagem celular foi cultivada até a confluência mínima de $90 \%$, em estufa com atmosfera controlada de $5 \%$ de $\mathrm{CO}_{2}$ a $37^{\circ} \mathrm{C}$.

\section{Titulação da toxina alfa in vivo e in vitro}

O título da toxina alfa em camundongo foi determinado realizando-se diluições seriadas, na base 1,2 em solução salina peptonada a 1\%, para estabelecimento da dose mínima mortal por mililitro (DMM/ $\mathrm{mL}$ ). Dois camundongos foram inoculados com 0,2 $\mathrm{mL}$ de cada diluição, por via intravenosa, e observados por 72 horas (BRITISH PHARMACOPOEIA, 1998).

Em cultivo celular, o título foi obtido em quadruplicata, sendo $100 \mu \mathrm{L}$ da toxina adicionados nos quatro primeiros poços da placa de 96 poços (Sarsted, EUA), e nos demais foram adicionados 50 $\mu \mathrm{L}$ de MEM suplementado. Procedeu-se a diluição da toxina na base 1,2 , e adicionou-se mais $50 \mu \mathrm{L}$ de MEM e $50 \mu \mathrm{L}$ do cultivo celular contendo $2,5 \times 10^{4}$ células, com volume final em cada poço de $150 \mu \mathrm{L}$. Como controle positivo utilizou-se $50 \mu \mathrm{L}$ de toxina alfa pura, $50 \mu \mathrm{L}$ de MEM e $50 \mu \mathrm{L}$ da suspensão de células, e como controle negativo $100 \mu \mathrm{L}$ de MEM e $50 \mu \mathrm{L}$ da suspensão de células. As placas foram incubadas a $37^{\circ} \mathrm{C}$ em estufa controlada com $5 \%$ de $\mathrm{CO}_{2}$ durante $48 \mathrm{~h}$. Após este período, corou-se a monocamada celular com solução de cristal violeta a 0,1\% em álcool (SALVARANi et al., 2011). O título da toxina alfa foi determinado pela visualização de $80 \%$ a $90 \%$ de efeito citopático sobre a monocamada celular.

\section{Padronização da toxina alfa in vivo e in vitro}

A padronização da toxina alfa em camundongos foi realizada utilizando-se o nível de teste $\mathrm{L}+/ 100$ conforme preconizado pelo Code of Federal Regulations (CFR-9, EUA, 2005). A padronização da toxina alfa na linhagem celular VERO foi realizada empregando-se diferentes níveis de teste: $\mathrm{L}+/ 10, \mathrm{~L}+/ 50, \mathrm{~L}+/ 100$ e $\mathrm{L}+/ 200$. Para isso, foram realizadas, dentro do intervalo das diluições 1:2 e 1:64, diluições seriadas na base 1,2 da toxina alfa, em quadruplicata, resultando em um volume final de $50 \mu \mathrm{L}$ por poço. Em seguida, 
foram adicionados $50 \mu \mathrm{L}$ de antitoxina alfa padrão em diferentes concentrações $(2 \mathrm{UI} / \mathrm{mL}, 0,4 \mathrm{UI} / \mathrm{mL}$, $0,2 \mathrm{UI} / \mathrm{mL}$ e $0,1 \mathrm{UI} / \mathrm{mL}$ ), de acordo com o nível de teste empregado. As placas foram incubadas a $37^{\circ}$ $\mathrm{C}$ em estufa úmida com $5 \%$ de $\mathrm{CO}_{2}$, durante uma hora. Após este período, foram adicionados $50 \mu \mathrm{L}$ de suspensão celular contendo $2,5 \times 10^{4}$ células e as placas foram novamente incubadas, nas mesmas condições anteriores, por $48 \mathrm{~h}$. Em seguida, o sobrenadante foi descartado, as placas coradas com solução de cristal violeta a 0,1\% em álcool (SALVARANI et al., 2010). A toxina alfa foi padronizada na maior diluição da toxina que resultou em efeito citopático de $80 \%-90 \%$ da monocamada celular.

Titulação de anticorpos contra toxina alfa in vivo e in vitro

Os soros de seis ovinos, seis caprinos e três pools de soro de oito dos coelhos foram titulados pelo teste de soroneutralização em camundongos contra a toxina alfa padronizada no nível de teste $\mathrm{L}+/ 100$, segundo metodologia descrita no CFR-9 (EUA, 2005). Como controle do teste, realizou-se a retrotitulação da toxina utilizando-se antitoxina padrão contendo 8,0UI/mL (SALVARANi et al., 2010).

Em cultivo celular, os títulos dos soros teste foram estabelecidos realizando-se diluições seriadas de cada um dos soros, utilizando-se fator de diluição 1,2 , com quatro repetições para cada diluição, em placas de 96 poços, resultando em volume final de $50 \mu \mathrm{L}$. Foram adicionados em cada poço $50 \mu \mathrm{L}$ da toxina padronizada no nível de teste $\mathrm{L}+/ 200$, que apresentou a melhor correlação com o nível de teste empregado na soroneutralização em camundongo. As placas foram incubadas, nas condições anteriormente descritas, por uma hora. Após este período, foi adicionada a suspensão celular contendo $2,5 \mathrm{x}$ $10^{4}$ células/poço. As placas foram novamente incubadas, por uma hora, e a leitura realizada após 48 horas. Para isso, o sobrenadante foi descartado e as placas foram coradas com solução de cristal violeta a 0,1\% em álcool (SALVARANi et al., 2011). Os títulos dos soros foram determinados pela primeira diluição que resultou em efeito citopático em 80\%-90\% da monocamada celular. Como controle negativo utilizou-se $100 \mu \mathrm{L}$ de MEM e $50 \mu \mathrm{L}$ da suspensão celular. No controle dos soros, em cada poço foram adicionados $50 \mu \mathrm{L}$ de cada soro teste, $50 \mu \mathrm{L}$ de MEM e $50 \mu \mathrm{L}$ da suspensão celular. Como controle do teste, foi realizada a retrotitulação da toxina utilizando-se antitoxina alfa padrão contendo 8,0 UI/mL ( SALVARANI et al., 2011).

Para análise estatística, empregou-se o teste de Lillieforms (LILLIEFORMS, 1967), para observar se os dados seguiam uma distribuição normal, os testes de Cochran e Bartlett (SNEDECOR; COCHRAN, 1989), para verificação da homogeneidade de variâncias, o teste " $\mathrm{t}$ " de Student, para comparação das médias dos tratamentos, e o quadrado de Pearson para estabelecer a correlação paramétrica entre os tratamentos aplicados (SAMPAIO, 1998).

\section{RESULTADOS E DISCUSSÃO}

O título da toxina alfa determinado em célula VERO foi de 30.814,04 ECP/mL (efeito citopático/ $\mathrm{ml}), 3,45$ vezes superior ao título de $8.916,10 \mathrm{DMM} /$ $\mathrm{ml}$ (dose mínima mortal/mL) obtido em camundongos, demonstrando a maior sensibilidade do sistema célular em detectar toxina alfa de C. novyi tipo B.

Ao contrário de outros autores (Амімото et al., 1998; BORRMANN; SCHULZE, 1999; BORRMANN et al., 2006), que avaliaram o efeito de toxinas em cultivo de células, utilizando o corante MTT (3-(4,5-dimetiltiazol2yl)-2,5-difenil brometo de tetrazolina), por meio de densidade óptica em leitor de ELISA, no presente trabalho, optou-se pela utilização da coloração com cristal violeta. Foi empregado o efeito citopático de $80-90 \%$ na monocamada celular devido ao efeito da toxina alfa de C. novyi tipo B na célula VERO. Pois esta, em contato com baixas concentrações da toxina alfa, apresenta alterações morfológicas, sem que necessariamente ocorra morte celular, mas não impede a visualização da descontinuidade da monocamada celular corada com cristal violeta e, consequentemente o estabelecimento do ponto de corte de $80-90 \%$ de feito citopático. Entretanto, a escolha dessa técnica justifica-se pelo baixo custo, praticidade e rapidez quanto à execução, dispensando o uso do microscópio ou do leitor de ELISA.

Na padronização da toxina alfa de C. novyi tipo B em cultivo de célula VERO, dentre os níveis de teste empregados, L+/200 foi o que apresentou melhor correlação com o nível de L+/100, empregado na padronização da toxina em camundongos. Otítulo da toxina alfa no sistema célula foi maior do que o título obtido no modelo animal, entretanto, o volume de toxina utilizado in vitro foi a metade do empregado no bioensaio, demonstrando uma proporcionalidade entre os níveis adotados e possibilitando a obtenção de títulos de soros semelhantes em ambos sistemas. Outro parâmetro considerado para a seleção deste nível de teste foi a capacidade de se detectar títulos mais baixos de anticorpos, aliado à utilização de menor concentração de toxina alfa na titulação dos soros no teste de potência, resultando em economia, quando comparado com os outros níveis de teste estudados.

Os títulos de anticorpos antitoxina alfa de $C$. novyi tipo B nos soros dos ovinos, caprinos e coelhos imunizados, determinados pela soroneutralização em camundongos e em cultivo de célula VERO, 
foram estatisticamente similares dentro do grupo de cada espécie $(p<0,05)$, demonstrando que não houve diferença significativa entre os dois modelos. Utilizando-se o método paramétrico do Quadrado de Pearson, observa-se uma correlação de 98,38\% (r $=0,9838$ com $p<0,01$ ) entre os títulos dos soros-teste determinados pela técnica de soroneutralização em camundongos e em cultivo de célula (Fig. 1). Essa alta correlação positiva entre os valores dos títulos de anticorpos obtidos nos dois modelos indica que as variações observadas nos títulos de anticorpos obtidos em camundongos acompanham proporcionalmente as variações dos títulos obtidos no sistema-célula.

BORRMANN et al. (2006) estabeleceram coeficientes de correlação de $90 \%$ entre o ensaio em cultivo de célula e o bioensaio animal na titulação de antitoxina alfa de C. novyi tipo B em soros de coelhos. A diferença entre a correlação encontrada por esses pesquisadores e a demonstrada no presente estudo pode ser atribuída às diferentes metodologias de leitura adotadas.

Correlações significativas entre títulos de anticorpos determinados pela soroneutralização em camundongo e em cultivo de célula também foram encontradas por outros autores. KNIGHT et al. (1990) relataram uma correlação de 91 ao avaliarem títulos da antitoxina alfa de C. septicum. Ainda, comparando os dois modelos experimentais, SouZA JúNIOR et al. (2010) demonstraram uma correlação de 98,33\% ao comparar a metodologia in vitro e in vivo para titulação de épsilon toxina de C. perfringens tipo D.

O uso do cultivo celular como modelo alternativo ao bioensaio animal demonstrou ser capaz de determinar títulos de anticorpos em soros de animais vacinados com toxoide alfa de $C$. novyi tipo $B$, de forma precisa, sensível, prática e rápida eliminandose a utilização de camundongos. Além disso, esta metodologia, quando comparada ao bioensaio em animais, tem custo efetivamente menor. Quando comparado a outros métodos sorológicos, como o ELISA e IDGA, somente o cultivo celular é capaz de detectar anticorpos neutralizantes. Os demais métodos detectam anticorpos contra qualquer epítopo presente na toxina, sendo pouco efetivos para a avaliação de respostas vacinais. Além disso, o sistema-célula não requer o uso de toxinas purificadas nem de anticorpos monoclonais como alguns ELISAs. O presente trabalho mostra ainda que, apesar de temida pelo risco de subjetividade, a coloração pelo cristal violeta seguida de leitura visual foi utilizada com sucesso, gerando uma alta correlação dos títulos obtidos in vivo e in vitro. Com isso, foi possível a substituição do MTT e consequentemente a não utilização do leitor de ELISA, o que pode facilitar a aplicação do teste em outros laboratórios.

Os resultados obtidos neste experimento permitem afirmar que esta técnica de soroneutralização em cultivo de célula VERO pode ser utilizada como método alternativo ao teste de soroneutralização em camundongos, considerado o teste "padrão-ouro", para avaliar a eficiência de toxoide alfa de C. novyi tipo $B$ em vacinas, pois reduz substancialmente a utilização de animais experimentais para este fim e atende, assim, aos anseios bioéticos.

Este experimento foi realizado conforme os princípios éticos da experimentação animal estabelecidos pelo Comitê de Ética em Experimentação Animal da Universidade Federal de Minas Gerais (n50/2008).

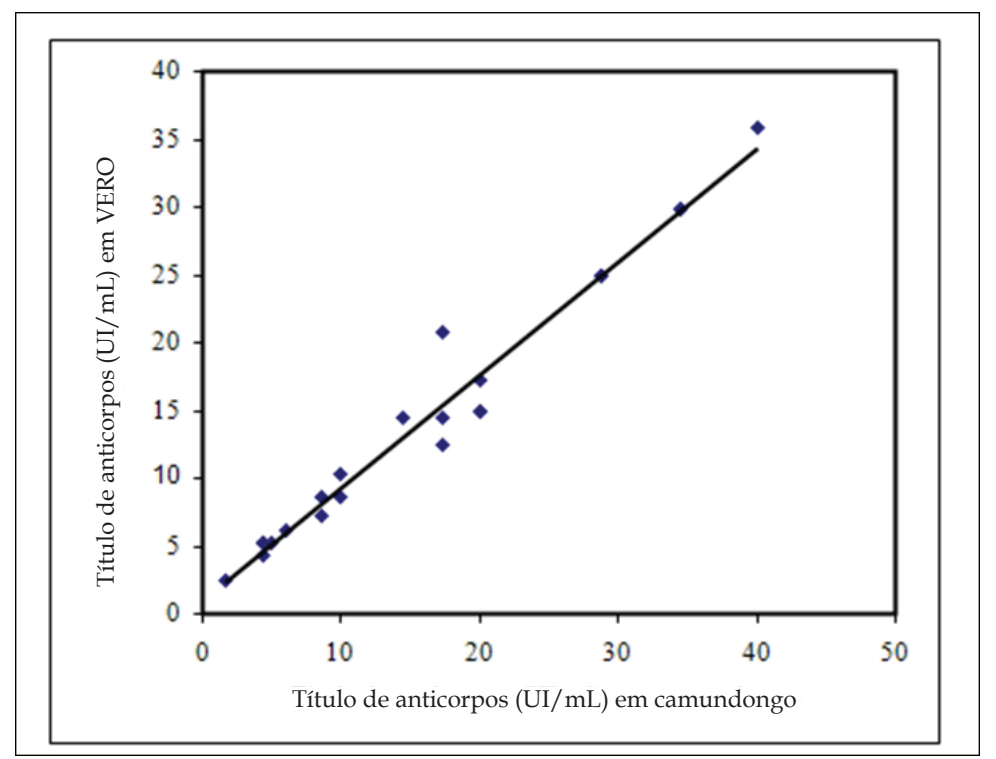

Fig. 1 - Correlação linear de Pearson entre os títulos de anticorpos antitoxina alfa de C. novyi tipo B em soros de ovinos, caprinos e coelhos imunizados com vacinas comerciais contendo toxoide alfa de C. novyi tipo B, determinados pelas técnicas de soroneutralização in vivo em camundongos e in vitro em cultivo de célula VERO $(\mathrm{r}=0,9838, \mathrm{p}<0,01)$. 


\section{AGRADECIMENTOS}

Este projeto foi financiado pela Fundação de Amparo à Pesquisa do Estado de Minas Gerais FAPEMIG e Coordenação Preventiva FEP-MVZ. Francisco Carlos Faria Lobato e Zélia Inês Portela Lobato foram apoiados com uma concessão do Conselho Nacional de Desenvolvimento Científico e Tecnológico - CNPq.

\section{REFERÊNCIAS}

AMIMOTO, K.; SASAKI, O.; ISOGAI, M.; KITAJIMA, T.; OISHI, E.; OKADA, N.; YASUHARA, H. The protective effect of Clostridium novyi tipo B alpha-toxoid against challenge with spores in guinea pigs. Journal Veterinary Medicine Science, v.60, n.6, p.681-685, 1998.

BALL, D.W.; VAN TASSELL, R.L.; ROBERTS, M.D.; HAHN, P.E.; LYERLY, D.M.; WILKINS, T.D. Purification and characterization of alpha toxin produced by Clostridium novyi tipo A. Infection and Immunity, v.61, n.7, p.2912-2918, 1993.

BORRMANN, E.; SCHULZE, F. Detection of Clostridium novyi tipo B a toxin by cell culture systems. FEMS Immunology Medical Microbiology, v.24, p.275-280, 1999.

BORRMANN, E.; SCHULZE, F.; CUSSLER, K.; HÄNEL, I.; DILLER, R. Development of a cell culture assay for the quantitative determination of vaccination-induce antibodies in rabbit sera against Clostridium perfringens epsilon toxin and Clostridium novyi alpha toxin. Veterinary and Microbiology, v.114, p.41-50, 2006.

BRASIL. Ministério da Agricultura. Portaria n. 49 de 12 de maio de 1997. Diário Oficial da União, Brasília, 16 de maio de 1997. Seção 1, p. 10168-10169.

BRITISH PHARMACOPEIA. Veterinary Antisera and Veterinary Vaccines. Sainte Ruffine: Maisonneuve, 1998. 1 CDROM

CARDELLA, M.A.; DUFF, J.T.; GOTTFRIED, C.; BEGEL, .JS. Studies on immunity to toxins of Clostridium botulinum. IV. Production and purification of type C toxin for conversion to toxoid. Jornaul of Bacteriology, v.75, p.360-365, 1958.

EBERT, E.; OPPLING, V.; WERNER, E.; CUSSLER, K. Development and prevalidation of two different ELISA systems for the potency testing of Clostridium perfringens $\beta$ - and $\varepsilon$-toxoid containing veterinary vaccines. FEMS Immunology and Medical Microbiology, v.24, p.299-311, 1999.

GONÇALVES, L.A.; LOBATO, Z.I.; SILVA, R.O.; SALVARANI, F.M.; PIRES, P.S.; ASSIS, R.A.; LOBATO, F.C. Selection of a Clostridium perfringens type D epsilon toxin producer via dot-blot test. Archives of Microbiology, v.191, p.847-851, 2009.

HATHEWAY, C.L. Toxigenic Clostridia. Clinical Microbiology Reviewss v.3, p.66-98, 1990. Disponível em: <http://www.ncbi.nlm.nih.gov/pmc/articles/ PMC358141/pdf/cmr00046-0078.pdf >. Acesso em: 30 nov. 2009. doi: 0893-8512/90/010066-33\$02.00/0.

KNIGHT, P.A.; TILLERAY, J.H.; QUEMINET, J. In vitro test for the measurement of veterinary Clostridial toxins, toxoids and antisera. I. Titration of Clostridium septicum toxins and antitoxins in cell culture. Biologicals, v.18, p.181-189, 1990.

LILLIEFORMS, H.W. On the Kolmogorov-Smirnov test for normality with mean and variance unknown. Journal of the American Statistical Association, v.62, p.399-402, 1967.

LOBATO, F. C. F.; ASSIS, R. A. Controle e profilaxia das clostridioses. Hora Veterinária, v.19, p.29-33, 2000.

LOBATO, F.C.F.; LIMA, C.G.R.D.; ASSIS, R.A.; PIRES, P.S.; SILVA. R.O.S.; SLAVARANI, F.M.; CARMO, A.O.; CONTIGLI, C.; KALAPOTHAKIS, E. Potency against enterotoxemia of a recombinant Clostridium perfringens type D epsilon toxoid in ruminants. Vaccine, v.28, p.6125-6127, 2010.

METZ, B.; HENDRIKSEN, C.F.; JISKOOT, W.; KERSTEN, G.F. Reduction of animal use in human vaccine quality control: opportunities and problems. Vaccine, v.20, p.2411-2430, 2002.

MIYASHIRO, S.; NASSAR, A.F.C.; SOUZA, O.S. Hepatite necrótica infecciosa em bovinos - Relato de caso. Biológico, São Paulo, v.68, p.123-126, 2006. Suplemento. Trabalho apresentado na REUNIÃO ANUAL DO INSTITUTO BIOLÓGICO, 19., 2006. Resumo 144/407. Disponível em: <http://www.biologico.sp.gov.br/docs/ bio/suplementos/v68_supl/p123-126.pdf>. Acesso em: 29 out. 2011.

SALVARANI, F.M.; LOBATO, Z.I.P.; ASSIS, R.A.; LIMA, C.G.R.D.; SILVA, R.O.S.; PIRES, P.S.; LOBATO, F.C.F. In vitro evaluation of the alpha toxoid from Clostridium septicum. Arquivo Brasileiro de Medicina Veterinária e Zootecnia, v. 62, n.4, p.778-783, 2010. Disponível em: < http://www.scielo.br/scielo.php?script=sci_artte xt\&pid=S0102-09352010000400002 $>$. Acesso em: 29 out. 2011. doi: 10.1590/S0102-09352010000400002.

SAMPAIO, I.B.M. Estatística aplicada à experimentação animal. Belo Horizonte: Fundação de Ensino e Pesquisa em Medicina Veterinária e Zootecnia, 1998. 221p.

SNEDECOR, G.W.; COCHRAN, W.G. Statistical methods. 8ed. Ames: Iowa State University Press, 1989. 593p.

SOUZA JÚNIOR, M.F.; LOBATO, Z.I.P.; PIRES, P.S.; SILVA, R.O.S.; SALVARANI, F.M.; ASSIS, R.A.; LOBA- 
TO, F.C.F. Padronização da titulação da toxina épsilon de Clostridium perfringens tipo D em linhagem contínua de células como alternativa ao bioensaio animal. Ciência Rural, v.40, n.3, p.600-603, 2010. Disponível em: <http:/ / www.scielo.br/scielo.php?pid=S0103$-84782010000300016 \&$ script $=$ sci_arttext\&tlng=pt $>$. Acesso em: 30 mar. 2010. doi: 10.1590/S010384782010005000024 .

TITBALL, R.; DUCHESNES, C.; GRANUM, P.E. Genus Clostridium: clostridia in medical, veterinary and food microbiology. European Concerted Action, 2006. 214p.

UZAL, F.A.; OLAECHEA, F.V.; VANNELLI, S.A. Un caso de hepatitis infecciosa necrosante en oveja sin Fasciola hepatica. Revista de Médicina Veterinária, Buenos Aires, v.77, p.377-379, 1996.
US. Code of Federal Regulations. Washington: Office of the Federal Register National Archives and Record Administration. 9CFR113.108. Sec. 113.108 Clostridium novyi Bacterin-Toxoid. 2008. Disponível em: <http:/ / ecfr. gpoaccess.gov/cgi/t/text/text-idx?c=ecfr\&sid=cfaf9409 $578171539 \mathrm{fb} 5804 \mathrm{ef1f} 97289 \& \mathrm{rgn}=$ div8\&view=text\&node =9:1.01.5.51.0.77.56\&idno=9 >. Acesso em: 9 nov. 2009.

WOOD, K.R. An alternative to the toxin neutralization assay in mice for the potency testing of Clostridium tetani, Clostridium septicum, Clostridium novyi type B and Clostridium perfringens type D epsilon components of multivalent sheep vaccines. Biologicals, v.19, p.281-286, 1991.

Recebido em 16/3/11

Aceito em 3/11/11 